\title{
Surgery and paediatric inflammatory bowel disease
}

\author{
Arun Kelay", Lucinda Tullie", Michael Stanton \\ Department of Paediatric Surgery, University Hospital Southampton, Southampton, UK \\ Contributions: (I) Conception and design: All authors; (II) Administrative support: None; (III) Provision of study materials or patients: None; (IV) \\ Collection and assembly of data: None; (V) Data analysis and interpretation: None; (VI) Manuscript writing: All authors; (VII) Final approval of \\ manuscript: All authors. \\ "These authors contributed equally to this work. \\ Correspondence to: Michael Stanton, MB, BS, MD, FRCS (Paed Surg), Consultant Paediatric Surgeon and Honorary Senior Lecturer. Department of \\ Paediatric Surgery, University Hospital Southampton, Tremona Road, Southampton SO16 6YD, UK. Email: Michael.Stanton@uhs.nhs.uk.
}

\begin{abstract}
The incidence of paediatric Crohn's disease (CD) and ulcerative colitis (UC) is increasing. Surgical intervention is required during childhood in approximately $25 \%$ of children diagnosed with CD, and for $10 \%$ of those diagnosed with UC. Although there is evidence that the rate of surgical intervention undertaken in children is decreasing since the introduction of biologic therapy, this may only represent a delay rather than true reversal of the risk of surgery. Surgery for CD is not curative and limited resection is the key principle thus preserving bowel length. For UC, subtotal colectomy is relatively curative; ileo-anal pouch anastomosis can be performed to restore bowel continuity.
\end{abstract}

Keywords: Paediatric inflammatory bowel disease (PIBD); Crohn's disease (CD); ulcerative colitis (UC)

Submitted May 28, 2019. Accepted for publication Aug 30, 2019.

doi: $10.21037 /$ tp. 2019.09 .01

View this article at: http://dx.doi.org/10.21037/tp.2019.09.01

\section{General introduction}

The incidence of both Crohn's disease (CD) and ulcerative colitis (UC) is increasing in children. Surgical intervention is required in a proportion of cases. For example, two recent studies reported that, for patients diagnosed at age $<17$ years, the risk of requiring surgery during childhood to be $24 \%$ for CD and $9 \%$ for UC $(1,2)$. In this cohort, diagnosis preceded surgery by median 9 months for CD and 2.2 years for UC. There appears to be evidence that the rate of surgery undertaken in children for paediatric inflammatory bowel disease (PIBD) is reducing in the era following the introduction of biological therapy (3). It is not clear yet as to whether this merely represents a delay in the timing of inevitable surgery, or a true reduction in the lifetime risk of requiring surgery.

\section{CD}

\section{Introduction}

Surgical intervention in paediatric CD represents a somewhat palliative strategy, albeit one which when appropriately timed can yield marked improvements in a patient's physical and psychological condition. Surgery is not curative. The underlying principal is to undertake a limited bowel resection, thus preserving bowel length for the future. One-fifth of patients will require surgery within three years of diagnosis, a cumulative incidence that rises to one-third by five years from diagnosis (4).

The surgical approach is broadly determined by the acuity of the patient's clinical condition, the anatomic region of the bowel affected and the underlying abnormality refractory inflammation, stricture, fistula or abscess/ phlegmon formation. European guidelines for the surgical management of paediatric CD have recently been published and will be referred to where appropriate (5).

\section{Indications for surgery}

\section{Emergency}

In the emergency setting, absolute indications for surgical intervention include perforation and complete bowel 
obstruction. The goals of surgery are therefore to control intra-abdominal infection, decompress obstructed bowel (often with a defunctioning ileostomy) thus allowing reintroduction of enteral nutrition. Major haemorrhage in the setting of Crohn's colitis is a rare occurrence, though potentially may require emergent laparotomy. Interventional radiological placement of an intra-abdominal drain may be required to treat an intra-abdominal collection.

The above scenarios are infrequently encountered in the biologic era; rather the majority of surgery in CD is undertaken as a planned procedure in the chronic setting. The decision to operate is reached through close consultation between the gastroenterologist, surgeon, patient and their family.

\section{Refractory CD}

Refractory disease is identified when a patient's symptoms or signs are clearly attributable to $\mathrm{CD}$, relapse whilst on optimised maintenance therapy and do not display an adequate response to induction therapy. A commonly encountered scenario is of fibro-stenotic disease, with a 'burnt-out' ileo-caecal stricture. Sequential MR enterography is very helpful in defining the length of the involved segment, response to medical treatment and disease burden at other sites. Radiological pre-stenotic dilatation is an indication that surgery is likely to be required, but should be correlated with clinical symptoms. The decision to proceed to surgery must be carefully considered, particularly in light of the risk of subsequent relapse and the future requirement for further surgery. The overriding principle is to undertake a limited resection. Usually a primary resection/anastomosis without stoma is possible. In adults, a recent randomized-controlled trial has suggested a role for early surgical resection in patients with short $(<40 \mathrm{~cm})$ segment non-stricturing disease, as an alternative to escalation to biologic therapy (6).

Within a Finnish cohort of 36 children who had undergone a bowel resection at a median of 10 years earlier, 94\% required further medical or surgical treatment for active disease, at a median of 1.8 years after surgery (7). Surgical complications occurred in $77 \%$ and further bowel resection was undertaken in 54\%. Analysis of a larger Danish cohort of 115 children with CD that had undergone at least one bowel resection, revealed cumulative clinical recurrence rates of $50 \%, 73 \%$ and $77 \%$ at 1,5 and 10 years postoperatively, respectively (8). Once again, a significant proportion (39\%) subsequently required further resection.

\section{Growth failure}

Growth impairment is a more frequent accompaniment of CD than UC, manifesting in $15-40 \%$ of patients (9) and potentially culminating in short stature in adulthood. This is detected by reduced height or weight velocity, delayed skeletal maturation and/or the delayed onset of puberty (10). Growth failure in CD is considered to have a multi-factorial aetiology (11), including uncontrolled inflammation resulting in increased energy requirements and cytokinemediated effects directly on bone, malnutrition secondary to inadequate nutrient intake as well as intestinal malabsorption; medications, with a particular focus on corticosteroid use; and growth hormone resistance with low levels of insulin-like growth factor.

Several retrospective studies have suggested that surgery enables catch-up growth and improved nutrition, as evidenced by significant increases in z-scores for height and weight as well as increased albumin levels (12-14). In light of this evidence, it is recommended that surgery can be performed in children with localised refractory disease coupled with growth failure despite optimal medical and nutritional therapy, with the aim of inducing remission and enabling catch-up growth (5). However, one recent study found that height did not increase after surgery, but that BMI did increase (1).

\section{Surgical options}

\section{Small bowel disease}

When CD is restricted to a single site-most commonly this is the ileo-caecal region-a limited resection is appropriate. The laparoscopic approach has gained popularity and should now be considered the gold standard. Laparoscopicassisted mobilisation of the right colon is undertaken. It is important for this to include taking down the hepatic flexure to avoid tension on the anastomosis. The ileocaecum can then be exteriorised through a small umbilical incision. Either a hand-sewn or stapled anastomosis can be performed. A recent Cochrane review of adult outcomes reported no difference in leak rates for hand-sewn $v s$ stapled anastomoses for non-cancer patients (15). Several studies have demonstrated that laparoscopic-assisted resection is at least comparable to the open approach (16-18). For example, in one series of thirty patients aged 10-18 years, no anastomotic leaks or wound infections occurred with a median follow-up of 9.7 years (18). Diamond et al reported a larger series of 135 patients, conversion to the open approach was required in $7 \%$ of patients. There was 
a relatively high incidence of post-operative small bowel obstruction described (19).

Isolated jejunal or ileal strictures are seen less commonly. Ileo-caecal resection is required for ileal segments close to the ileo-caecal valve. When multiple small bowel segments are involved, strictureplasty may be preferable in order to preserve bowel length and thereby minimise the long-term risk of short bowel syndrome. There is conflicting evidence from the literature regarding the efficacy of strictureplasty, in particular relating to disease recurrence as resection is not undertaken. An Italian series comparing the outcomes of patients with ileal or ileo-colonic strictures treated with either strictureplasty or resection did not identify any significant difference in relapse rate (20). Conversely, an English study suggested that resection is more effective at treating stenotic CD as the number of patients who required further surgery was significantly less than following strictureplasty (3/21 vs. 11/19) (21).

\section{Large bowel disease}

Children affected by pan-colonic CD that is refractory to medical therapy usually undergo a subtotal colectomy. Later ileo-rectal anastomosis can be considered. A primary resection/anastomosis may be possible in the absence of pre-operative risk factors for complications such as corticosteroids use or poor nutritional status. Otherwise, the anastomosis should be deferred until the patient's medical condition is optimized and staged procedures undertaken. Segmental colonic resection may be applied to Crohn's colitis (22), however this pattern of bowel involvement carries an increased risk of relapse with the attendant risk of subsequent colectomy. Ileostomy formation only can be a temporising measure, enabling improvement in the patient's overall condition prior to formal colonic resection. Creation of an ileal pouch-anal anastomosis (IPAA) in CD is generally discouraged due to the high risk of pouch failure, as compared with UC (23). Rectal strictures are difficult to manage in children. Although trans-anal resection has been described in a small series (24), defunctioning stoma is often necessary.

\section{Peri-anal disease}

Peri-anal CD may manifest as peri-anal abscess/fistulae, skin tags, fissures, and in advanced cases, as anal stenosis. Peri-anal abscess may be the initial presentation of CD. A Canadian retrospective single-institution review reported that $62 \%$ of a cohort of $325 \mathrm{CD}$ patients developed peri- anal disease, with these features constituting part of the initial presentation in $47 \%$ (25). This occurred in patients irrespective of the particular pattern of gastric, small or large bowel involvement, progressing to become a chronic issue in $25 \%$ of the cohort. Analysis of 6,679 patients over an 8-year period from an American multi-centre prospective observational cohort demonstrated that $21 \%$ suffered from peri-anal disease (26). Estimated probabilities of developing perianal disease over time were calculated, with probabilities of $17 \%$ and $26 \%$ at 3 and 5 years after the initial CD diagnosis, respectively.

There also appears to be a more aggressive phenotype within the overall group of patients with perforating perianal disease (PPD)_defined as the presence of peri-anal abscesses and/or fistulae. This phenotype manifests as PPD in patients whilst on maintenance therapy, as opposed to those who present with features of PPD (27). The former group was more likely to be younger and male, with a significantly increased number of non-perianal bowel procedures, including diverting ileostomy and colectomy.

The guiding priority in the surgical management of perianal disease is to maintain continence whilst controlling symptoms. Here the discussion will focus on the investigation and management of patients with PPD. Other peri-anal problems (e.g., skin tags) should be managed without surgery.

\section{Peri-anal abscess and fistula}

PPD can be present at the time of the initial CD diagnosis, and was identified within 30 days of diagnosis in approximately $10 \%$ of an American cohort of 276 children (28). Over a median follow-up period of 4.5 years, $15 \%$ of another American cohort of 215 patients developed PPD, $12 \%$ of whom presented with these features. Peri-anal fistulae are traditionally described using the precise Parks classification (29), which relates the path of the fistula to the position of the external and internal anal sphincters. This applies to fistulae-in-ano in general, rather than specifically within the context of CD, and can be determined at operation. A simpler system divides fistula into those that are simple or complex. A simple fistula is a single, low inter-sphincteric or trans-sphincteric tract with an internal opening close to the anal verge, without associated rectal inflammation or abscess formation. In contrast, a complex fistula may comprise multiple tracts with an internal opening cranial to the sphincter muscles and concomitant rectal inflammation, stenosis or abscess formation (30).

Evaluation of a patient with suspected peri-anal disease 
involves external inspection, MR scan of the pelvis and examination under anaesthesia with procto-sigmoidoscopy. When combined, these investigations should delineate the origin of the fistula(e), demonstrate the course of the fistulous tract and determine the presence of simultaneous rectal inflammation or peri-anal abscess. If the peri-anal disease has developed subsequent to the initial diagnostic investigations for $\mathrm{CD}$, then the small and large bowel should also be re-assessed as this can influence overall management (5).

In general, multi-modality treatment with a combination of surgery, antibiotics and biologics must be implemented to adequately treat peri-anal fistulae in $\mathrm{CD}$. The goal is to ultimately achieve closure of the fistulous tract(s) and thereby halt drainage. Simple peri-anal fistulae with no associated symptoms warrant observation alone. If symptoms subsequently develop then placement of a loose, non-cutting seton is favoured. Fistulotomy may be considered if the tract is sufficiently superficial, but the potential for poor-healing usually means that seton placement is preferable. Cutting setons are contra-indicated due to the risk of damage to the anal sphincter mechanism and subsequent incontinence. Antibiotics are also commonly administered for simple fistulae; metronidazole and ciprofloxacin are the most frequently employed.

Complex peri-anal fistulae are treated with biologic agents for both induction and maintenance medical therapy, only after surgical drainage of any associated abscess and thus treatment of any septic focus. Refractory peri-anal disease, with recurrent sepsis, may necessitate diversion of the faecal stream with a stoma to improve chances of healing.

As part of a randomised controlled trial evaluating the safety and efficacy of infliximab therapy in 112 children with moderate to severely active luminal CD (REACH trial), a post-hoc analysis was performed to assess the response of peri-anal disease to this biologic agent (31). An improvement was observed by week 2 in $41 \%$ ( 9 of 22 ) of patients, rising to $73 \%$ ( 16 of 22 ) by week $54 ; 15$ of these patients had achieved a complete response to therapy. The adult literature suggests that seton drainage together with infliximab therapy produces superior response rates compared to either one alone $(32,33)$. A retrospective Finnish review of 13 adolescents with peri-anal fistulae treated in this way showed that more than $90 \%$ responded (34). At a median of 8 weeks, a complete response was seen in $77 \%$ with a partial response in $15 \%$. Follow-up (median of 2 years) revealed that $70 \%$ were asymptomatic in terms of peri-anal disease.
Median duration of seton placement was 8 months.

\section{Other fistulising CD}

Fistulous tracts can also develop between loops of bowel (entero-enteric fistulae), bowel and bladder (entero-vesical fistulae), bowel and skin (entero-cutaneous fistulae) as well as from bowel to the gynaecological organs i.e., rectovaginal and anal-introital fistulae.

There is a subset of patients with particularly severe perianal disease, termed 'highly destructive perianal disease' (HDPD) (35) who have been described as developing rectovaginal and recto-labial fistulae, otherwise uncommon in the paediatric population.

Entero-enteric fistulae are dealt with by resection of the diseased bowel segments and primary anastomosis in healthy bowel to restore intestinal continuity. The general surgical principal is to resect the affected proximal segment and oversaw the distal segment. Entero-vesical fistulae are managed by resection of the involved part of the bladder and primary bladder closure.

\section{Peri-operative considerations}

\section{Pre-operative medication Corticosteroids}

Corticosteroid administration in the pre-operative period should be minimized, or ideally stopped if at all practicable, to reduce the risk of complications. A large study of 8,260 adults with $\mathrm{CD}$ who underwent major abdominal surgery between 2005 and 2012 demonstrated that pre-operative steroid use was associated with a significantly higher risk of complications $(22.6 \%$ vs. $18.5 \%)$ when compared to those who did not receive steroids (36). Intra-abdominal infections, sepsis and venous thrombo-embolism (VTE) were the specific complications that occurred with increased frequency in the pre-operative steroid group, although 30-day mortality was not influenced by steroid use.

\section{Immunomodulators}

In the adult literature, a meta-analysis has been reported to determine the potential impact of pre-operative immunomodulator therapy (thiopurines, methotrexate) on post-operative complications (37). Six studies including 1316 patients that assessed overall complications were selected. There was no statistically significant difference identified between patients that did or did not receive thiopurines for all post-operative complications (OR: 1.31). Infectious complications were considered separately, and this analysis of seven studies incorporating 1,699 patients 
did reveal a significantly higher rate of infectious postoperative complications in patients that received thiopurines (OR: 1.45). In children, data is lacking on the influence of thiopurines in post-operative outcomes.

\section{Biologic agents}

There is similar debate surrounding the influence of biologic agents on post-operative complications (38). A meta-analysis of adult patients detected a statistically significant association between pre-operative infliximab therapy and overall, infectious and non-infectious postoperative complications. These results were taken to reflect a modest increase in overall early post-operative complications, particularly those of an infectious nature. Biologic agents have a relatively short half-life and influence surgical outcomes less than steroids. In children, several studies have not detected a difference in post-operative complications in children who did and did not receive biologic agents pre-operatively, albeit with relatively small numbers (39-41).

\section{Nutritional optimisation}

Poor pre-operative nutritional status-which may be reflected by hypoalbuminemia-poses a risk for intraabdominal sepsis in the post-operative period (42-44). The development of complications including anastomotic leak, intra-abdominal abscess and entero-cutaneous fistula has been noted to be significantly associated with a low pre-operative albumin level ( $<30 \mathrm{~g} / \mathrm{L})(42)$. Nutritional supplementation through either enteral or parenteral routes is therefore recommended. Enteral nutrition is preferred as it is physiological, does not engender the risks of sepsis associated with central venous lines and is cheaper. A small group of patients from Sweden that received pre-operative total parenteral nutrition (TPN) before undergoing bowel resection and primary anastomosis did not experience any significant early post-operative complications (44). This was in comparison to $28 \%$ of matching controls that did experience complications.

\section{Early post-operative complications}

These mainly consist of anastomotic leak, small bowel obstruction, wound healing complications, fistula formation and venous thrombo-embolism (VTE). An English study of 62 patients over a 10 -year period determined that $22 \%$ (13 of 62) of patients developed early complications (1). The rate of complications is influenced by the extent of resection and the segment affected. A Danish study of 115 patients demonstrated a complication rate of $6 \%$ (1 of 16 ) and $24 \%$
(13 of 54) for ileal or ileo-caecal resections, respectively; $42 \%$ (5 of 12 ) or $52 \%$ (11 of 21 ) of patients undergoing hemi-colectomy or total colectomy, respectively, developed complications (8).

Children with CD are at increased risk of VTE in the post-operative period. Analysis of a population database detailing paediatric in-patient stays including 68,394 patients revealed an incidence of VTE of 117.9/10,000 (45). The relative risk of VTE was 2.36. Identified risk factors for VTE included older age, presence of a central venous catheter, administration of TPN and the diagnosis of a hyper-coagulable disorder. These factors must be taken into consideration in the post-operative period to guide the institution of mechanical and/or pharmacological thromboprophylaxis.

\section{Late post-operative complications}

\section{Bowel obstruction}

This may occur as consequence of adhesions or an anastomotic stricture. A Swedish study of 36 patients that had previously undergone bowel resection and been followed up for at least 2 years, revealed that 12 (33\%) developed adhesional obstruction; in $9(25 \%)$ an anastomotic stricture was responsible for bowel obstruction (7). Endoscopic balloon dilatation of an anastomotic stricture is usually attempted as a first line treatment.

\section{Vitamin B12 malabsorption}

Extensive terminal ileal resections may lead to malabsorption of vitamin B12 (46). If allowed to progress undetected, megaloblastic anaemia can develop as well as neuropathy and/or myelopathy (sub-acute combined degeneration of the spinal cord). One protective factor within the paediatric population is the potential for adaptation of the remaining small bowel. Vitamin B12 malabsorption has been observed to resolve 6-8 years after ileal resection in children, presumably secondary to adaptation, although resolution of bacterial overgrowth could also have contributed (47). It is recommended that vitamin B12 levels be routinely monitored in patients who have had more than $20 \mathrm{~cm}$ of their terminal ileum resected (5).

\section{Bile acid malabsorption (BAM)}

The terminal ileum is also the site of bile acid re-absorption and therefore plays a crucial role in the entero-hepatic circulation of bile salts. Malabsorption of bile acids most commonly manifests as diarrhoea. A German study 
measured 7 alpha-hydroxy-4-cholesten-3-one (C4) in the serum of patients with $\mathrm{CD}$ as a semi-quantitative test for BAM (48). They determined that patients who had undergone ileal resections of $10-30 \mathrm{~cm}$ had raised C4 levels indicating BAM. Diagnosis is usually made on the basis of resolution of diarrhoea with administration of empirical bile-acid binding agents such as cholestyramine. Patients with persistent diarrhoea in the context of quiescent disease or minimally-active disease following ileal resection should be suspected to have BAM and be treated accordingly (5).

\section{Surgery for UC}

\section{Introduction}

Disease activity in UC may be evaluated and classified as mild, moderate or severe based upon stool frequency, haemodynamic parameters and laboratory markers (such as haemoglobin and $\mathrm{C}$ reactive protein). The Paediatric Ulcerative Colitis Activity Index (PUCAI) is a validated 6-point scoring system quantifying severity of symptoms and their impact on quality of life $(49,50)$. It is used to both assess severity of disease ( $<10$ remission, mild disease $10-34$, moderate 35-64 and severe disease $>65$ ) and response to treatment.

Surgery in UC is indicated in both elective and emergency circumstances. In the elective setting this may due to disease refractory to medical therapy, significant side effects of medical therapy, steroid dependent disease or, more rarely in children, where dysplasia or malignancy is present. The reported rate of colectomy performed has not changed recently (51) and in a Canadian dataset there was no change in rates of colectomy performed for UC between 1994-2007 (52). The long-term influence of biologic therapies remains to be seen.

Depending upon the clinical status of the patient, surgery in pediatric UC may involve 1-3 staged procedures. A subtotal colectomy-almost complete resection of the colon leaving an end ileostomy and oversewn rectal stump-is the first of these. This is the recommended operation for acute severe colitis (ASC). The second stage is a restorative proctocolectomy, with removal of the remaining rectum (whilst preserving the anal sphincter), and either an ileal pouchanal anastomosis (IPAA) to create a reservoir for faeces, or a straight ileo-rectal (or ileo-anal) anastomosis. This procedure may be performed with (or without) a covering ileostomy, which is subsequently closed a few months later $\left(3^{\text {rd }}\right.$ stage), after radiological assessment of the pouch.

\section{ASC}

In ASC, which may be defined as a PUCAI of $>65$, children are clinically unwell with symptoms such as severe abdominal pain, diarrhoea and bloody stools. In one reported series, ASC was the presentation in $9 \%$ children with UC and by 2 years, almost a quarter of children had experienced at least one episode (53). Another multicentre study reported rates of ASC in $15 \%$ children within 3 months of diagnosis (54). Children with ASC require hospitalisation for intravenous steroid therapy, first line medical treatment in ASC, found to be the most important factor in reduction of mortality in UC ASC (55). Progression to second line medical therapy (either infliximab of calcineurin inhibitors) is indicated with ongoing active symptoms (PUCAI score $>45$ ) at 72 hours of IV steroid treatment (56).

A number of circumstances may warrant emergency subtotal colectomy with end ileostomy formation. These include a failure to respond to both first- and second-line medical treatment and evidence of either visceral perforation or toxic megacolon. Toxic megacolon is a rare complication of ASC occurring in 1-2\% of paediatric cases. It is defined as radiographic transverse colon diameter $>56 \mathrm{~mm}$ (or $>40 \mathrm{~mm}$ in those $<10$ years) alongside systemic toxicity (fever, tachycardia) or biochemical disturbance $(57,58)$. ECCO/ ESPHAGAN guidelines recommend prompt surgical evaluation in toxic megacolon with conservative management reserved for those with a stable clinical condition, and urgent colectomy if no clinical improvement is apparent after 24-72 hours of treatment (56).

Biologic therapies (infliximab) and calcineurin inhibitors have overall reduced colectomy rates, in the short term, from between $40-70 \%(59-61)$ to $10-20 \%(57,62)$. In one study, 33 patients who failed to respond to IV corticosteroids received rescue therapy with infliximab in ASC and $76 \%$ were discharged without colectomy and $55 \%$ had a sustained response at 1 year of follow-up (62). However, a significant proportion (50-60\%) with ASC who respond to medical therapy will go onto require a colectomy within 2 years $(62,63)$.

In those who have an emergency subtotal colectomy and end ileostomy, completion proctectomy and IPAA/ IRA formation is postponed until their clinical condition has improved with ileostomy reversal undertaken several months later. Laparoscopic subtotal colectomy even in the setting of ASC if recommended if appropriate expertise is available (ECCO/ESPGHAN guideline). 


\section{Elective surgery for ambulant patients}

Elective colectomy is undertaken for clinically well patients with active or steroid-dependent disease despite optimised medical therapy or if dysplasia is present (64). In this patient cohort, restorative procto-colectomy and IPAA alongside a covering ileostomy is the recommended first stage procedure. The covering ileostomy is subsequently reversed (64).

With regards to surgical approach, laparoscopic colectomy and pouch formation has been demonstrated to be both feasible and safe in adults and children $(19,65,66)$. Data from the American College of Surgeons National Surgical Quality Improvement Program database (ACSNSQIP, 2005 to 2008) demonstrated that a laparoscopic approach was used in $29.2 \%$ of all cases (both adult and pediatric) undergoing a colectomy, with rates increasing annually, up to $41.3 \%$ in 2008 (67). Whilst a laparoscopic approach increases procedure length, cosmesis favours laparoscopy and other outcomes including length of stay, surgical complications and functional outcomes are comparable between open and laparoscopic techniques $(19,68-70)$.

Restorative proctocolectomy and pouch formation without a covering ileostomy has been reported with several single centre series documenting no increased morbidity, with regards to anastomotic leak/stricture or episodes of pouchitis. However, the retrospective data in these series and the relatively small patient numbers would preclude any statistically significant differences $(71,72)$ and consequently guidelines recommend a covering ileostomy (64).

A variety of reconstruction techniques exist-IPAA with either a 'J', 'S', or ' $W$ ' reservoir, and straight ileoanal anastomosis (SIAA). These can be undertaken with either hand-sewn or stapled anastomotic techniques. In the pediatric population, the 'J' IPAA and SIAA are by far the most common techniques used. A meta-analysis of pediatric series (306 patients) reported higher failure rate with SIAA (15\%) when compared with IPAA (8\%) (73). Furthermore, higher stooling frequency, both day and night-time, was reported with SIAA (73-75). However, a more recent multicentre study of 203 paediatric proctocolectomies, and either SIAA or IPAA, found similar surgical complication rates including anastomotic dehiscence/leak/stricture and adhesional obstruction. Whilst SIAA patients had increased stooling frequency, IPAA had higher rates of symptomatic pouchitis (75). Hand-sewn and stapled anastomotic techniques had similar rates of complications and comparable functional outcomes (76-79).

\section{Complications and outcomes}

Surgery in UC (unlike for CD) may be curative but is associated with significant complications. Over a 12 -year period (1997 to 2009), a population-based American study found that whilst colectomy rates have remained stable, the rate of complications increased annually at a rate of $1.1 \%$ (51). Complication rates are, unsurprisingly, higher after colectomy undertaken as an emergency procedure and in children with poorer nutritional status and concurrent steroid requirement $(80,81)$. In one study, up to a third of patients undergoing a colectomy for UC were reported to have at least one complication, including infection (urine, abscess or generalised sepsis) bleeding and thrombosis (80). Peri-operative antibiotic and thrombo-embolic prophylaxis is therefore recommended (82). Other reported complications include leak from the oversewn rectal stump, and both early and late instances of small bowel obstruction (in up 50\%) which necessitated operative intervention in up to a third of affected patients $(2,83,84)$. When follow-up was extended up to a decade, complication rates up to $75 \%$ were reported (83).

Early complications related to IPAA include anastomotic leak $(13 \%)$, stenosis or stricture $(27 \%)$ and abscess formation (12\%) (83). Pouchitis, a non-specific and idiopathic inflammation of the ileal reservoir is, however, the most frequent long-term complication and the most common cause of pouch failure. The aetiology is unclear but is thought to be due to a complex interaction between host immunity and microbiome of the pouch giving rise to symptoms of increased stool frequency, urgency, tenesmus, abdominal pain, and rectal bleeding (85). 'Cuffitis'inflammation of the cuff of rectal mucosa, between the dentate and anastomosis, may cause similar symptoms to pouchitis. Rates of pouchitis of 50-67\% have been reported in studies documenting up to 10-year follow-up, including a recent multi-centre cohort study (86-89). In $26 \%$ the pouchitis was chronic. De novo diagnosis of CD is reported in up to $20 \%$ of adult patients undergoing IPAA $(90,91)$.

Frequency of episodes and duration of pouchitis has been shown to be unaffected by pouch type, patient age, and operative technique (70). PUCAI score at the time of diagnosis was a predictive risk factor for development of pouchitis (92) and there is some evidence that surgical experience impacts upon development of chronic pouchitis. One UK study demonstrated pouchitis rates of $15 \%$ in adults for surgeons undertaking at least 10 procedures annually compared with $41 \%$ in those performing less 
than 10 (93). Acute pouchitis is managed with antibiotic monotherapy. A recent RCT showed some superiority of ciprofloxacin compared with metronidazole monotherapy in the treatment of pouchitis (94). Chronic pouchitis may be managed with dual antibiotic therapy, or oral budesonide in those who fail to respond to antibiotics (95). There has been some success with infliximab monotherapy in refractory pouchitis, with one study demonstrating an $88 \%$ clinical response after 10 weeks of treatment (96).

Following restorative proctocolectomy and IPAA, stool frequency is, on average, 4-6 per day and 0-1 per night. Continence rates between $44 \%$ and $73 \%$ are reported $(70,83,97)$. Almost half of patients in one study reported using medication to control frequency of bowel motions (83). There is some evidence that continence improves over time, with one study demonstrating $72 \%$ day and night time continence after 5 years follow-up (97).

Overall reported quality of life following IPAA is good, with $80 \%$ reporting better quality of life following the procedure $(83,97)$. Increased frequency of bowel motions and surgical complications were both associated with decreased quality of life (83). In one study, there was no significant difference in self-reported physical, emotional and social functioning or overall quality of life between those undergoing proctocolectomy and IPAA for UC and age-matched controls (83). $90 \%$ of patients in another study would recommend IPAA surgery to others (97). Pouch abandonment and conversion to permanent ileostomy following IPAA undertaken in childhood is reported to occur in $9 \%$ and $13 \%$ of patients in two series, albeit with a relatively short median follow-up of 7 and 4 years, respectively $(98,99)$.

Surgery for UC is frequently performed during reproductive years due to timing of disease onset. Whilst UC in itself probably does not have a significant impact on female fertility/fecundity, several studies have demonstrated decreased female fecundity following IPAA (100-103). A recent meta-analysis found a pre-IPAA infertility rate of $20 \%$, increasing to $63 \%$ post-procedure; an increase in the relative risk of infertility of 3.9 (104). However, the review authors acknowledge the heterogeneity of papers within the analysis, particularly in the lack of a standard definition of infertility which varied from inability to become pregnant within a year of attempting, probability of becoming pregnant/month of unprotected intercourse (fecundity), self-reported "difficulty" in conceiving and, in some papers, there was no definition at all (104).

With the extensive pelvic dissection associated with proctocolectomy and IPAA, the postulated cause for fertility decline is pelvic scarring and adhesions causing tubal abnormalities. Several papers have demonstrated tubal abnormalities following IPAA, including tubal occlusion and adherence to the pelvic floor in up to $50 \%$ patients who underwent hysterosalpingography following IPAA (105). Similar rates of tubal problems have been observed following proctocolectomy and end-ileostomy formation $(106,107)$. Some studies have attempted to identify specific risk factors predisposing to post-IPAA infertility. However, only post-operative blood transfusion was found to be significant, most likely as a proxy for difficult pelvic dissection rather than being a causative factor in its own right $(108,109)$. Laparoscopic IPAA, which is increasingly performed, has been shown to reduce the risk of infertility, most likely via reducing adhesions, scarring and tubal obstruction. A study comparing fertility between laparoscopic IPAA and controls reported an overall infertility rate of $27 \%$ with no difference in reported fertility between groups (110). These infertility risks should be discussed with women prior to embarking upon surgery for UC and guidelines recommend a laparoscopic approach where possible (64).

\section{Acknowledgments}

None.

\section{Footnote}

Conflicts of Interest: The authors have no conflicts of interest to declare.

Ethical Statement: The authors are accountable for all aspects of the work in ensuring that questions related to the accuracy or integrity of any part of the work are appropriately investigated and resolved.

\section{References}

1. Blackburn SC, Wiskin AE, Barnes C, et al. Surgery for children with Crohn's disease: indications, complications and outcome. Arch Dis Child 2014;99:420-6.

2. Ashton JJ, Versteegh HP, Batra A, et al. Colectomy in pediatric ulcerative colitis: A single center experience of indications, outcomes and complications. J Pediatr Surg 2016;51:277-81.

3. Ashton JJ, Borca F, Mossotto E, et al. Increased 
prevalence of anti-TNF therapy in paediatric inflammatory bowel disease is associated with a decline in surgical resections during childhood. Aliment Pharmacol Ther 2019;49:398-407.

4. Vernier-Massouille G, Balde M, Salleron J et al. Natural history of pediatric Crohn's disease: a population-based cohort study. Gastroenterology 2008;135:1106-13.

5. Amil-Dias J, Kolacek S, Turner D, et al. Surgical Management of Crohn Disease in Children: Guidelines From the Paediatric IBD Porto Group of ESPGHAN. J Pediatr Gastroenterol Nutr 2017;64:818-35.

6. Ponsioen CY, de Groof EJ, Eshuis EJ, et al. Laparoscopic ileocaecal resection versus infliximab for terminal ileitis in Crohn's disease: a randomized controlled openlabel, multicentre trial. Lancet Gastroenterol Hepatol 2017;2:785-92.

7. Piekkala M, Pakarinen M, Ashorn M, et al. Long-term outcomes after surgery on pediatric patients with Crohn disease. J Pediatr Gastroenterol Nutr 2013;56:271-6.

8. Hansen LF, Jakobsen C, Paerregaard A, et al. Surgery and postoperative recurrence in children with Crohn disease. J Pediatr Gastroenterol Nutr 2015;60:347-51.

9. Griffiths AM, Growth retardation in early-onset inflammatory bowel disease: should we monitor and treat these patients differently? Dig Dis 2009;27:404-11.

10. Griffiths AM, Nguyen P, Smith C, et al. Growth and clinical course of children with Crohn's disease. Gut 1993;34:939-43.

11. Walters TD, Griffiths AM. Mechanisms of growth impairment in pediatric Crohn's disease. Nat Rev Gastroenterol Hepatol 2009;6:513-23.

12. Pacilli M, Eaton S, Fell JM, et al. Surgery in children with Crohn disease refractory to medical therapy. J Pediatr Gastroenterol Nutr 2011;52:286-90.

13. Baldassano RN, Han PD, Jeshion WC, et al. Pediatric Crohn's disease: risk factors for postoperative recurrence. Am J Gastroenterol 2001;96:2169-76.

14. Hojsak I, Kolacek S, Hansen LF, et al. Long-term outcomes after elective ileocecal resection in children with active localized Crohn's disease - a multicenter European study. J Pediatr Surg 2015;50:1630-5.

15. Choy PY, Bissett IP, Docherty JG, et al. Stapled versus handsewn methods for ileocolic anastomosis. Cochrane Database Syst Rev 2011;7:CD004320.

16. Milsom JW, Hammerhofer KA, Böhm B, et al. Prospective, randomized trial comparing laparoscopic vs. conventional surgery for refractory ileocolic Crohn's disease. Dis Colon
Rectum 2001;44:1-8.

17. Bonnard A, Fouquet V, Berrebi D, et al. Crohn's disease in children. Preliminary experience with a laparoscopic approach. Eur J Pediatr Surg 2006;16:90-3.

18. Laituri CA, Fraser JD, Garey CL, et al. Laparoscopic ileocolectomy in pediatric patients with Crohn's disease. J Laparoendosc Adv Surg Tech A 2011;21:193-5.

19. Diamond IR, Gerstle JT, Kim PC, et al. Outcomes after laparoscopic surgery in children with inflammatory bowel disease. Surg Endosc 2010;24:2796-802.

20. Romeo E, Jasonni V, Caldaro T, et al. Strictureplasty and intestinal resection: different options in complicated pediatric-onset Crohn disease. J Pediatr Surg 2012;47:944-8.

21. Bamford R, Hay A, Kumar D. Resection leads to less recurrence than strictureplasty in a paediatric population with obstructive Crohn's disease. Surg Res Pract 2014;2014:709045.

22. Smith NP, Ba'ath ME, Perry D, et al. BAPS UK inflammatory bowel disease surgical practice survey. J Pediatr Surg 2007;42:296-9.

23. Shen B, Remzi FH, Hammel JP, et al. Family history of Crohn's disease is associated with an increased risk for Crohn's disease of the pouch. Inflamm Bowel Dis 2009; 15:163-70.

24. Lawal TA, Frischer JS, Falcone RA, et al. The transanal approach with laparoscopy or laparotomy for the treatment of rectal strictures in Crohn's disease. J Laparoendosc Adv Surg Tech A 2010;20:791-5.

25. Palder SB, Shandling B, Bilik R, et al. Perianal complications of pediatric Crohn's disease. J Pediatr Surg 1991;26:513-5.

26. Adler J, Dong S, Eder SJ, et al. Perianal Crohn Disease in a Large Multicenter Pediatric Collaborative. J Pediatr Gastroenterol Nutr 2017;64:e117-24.

27. Short SS, Dubinsky MC, Rabizadeh S, et al. Distinct phenotypes of children with perianal perforating Crohn's disease. J Pediatr Surg 2013;48:1301-5.

28. Keljo DJ, Markowitz J, Langton C, et al. Course and treatment of perianal disease in children newly diagnosed with Crohn's disease. Inflamm Bowel Dis 2009; 15:383-7.

29. Parks AG, Gordon PH, Hardcastle JD. A classification of fistula-in-ano. Br J Surg 1976;63:1-12.

30. de Zoeten EF, Pasternak BA, Mattei P, et al. Diagnosis and treatment of perianal Crohn disease: NASPGHAN clinical report and consensus statement. J Pediatr Gastroenterol Nutr 2013;57:401-12. 
31. Crandall W, Hyams J, Kugathasan S, et al. Infliximab therapy in children with concurrent perianal Crohn disease: observations from REACH. J Pediatr Gastroenterol Nutr 2009;49:183-90.

32. Hyder SA, Travis SP, Jewell DP, et al. Fistulating anal Crohn's disease: results of combined surgical and infliximab treatment. Dis Colon Rectum 2006;49:1837-41.

33. Topstad DR, Panaccione R, Heine JA, et al. Combined seton placement, infliximab infusion, and maintenance immunosuppressives improve healing rate in fisulizing anorectal Crohn's disease: a single-center experience. Dis Colon Rectum 2003;46:577-83.

34. Hukkinen M, Pakarinen MP, Piekkala M, et al. Treatment of complex perianal fistulas with seton and infliximab in adolescents with Crohn's disease. J Crohns Colitis 2014;8:756-62.

35. Markowitz J, Grancher K, Rosa J, et al. Highly destructive perianal disease in children with Crohn's disease. J Pediatr Gastroenterol Nutr 1995;21:149-53.

36. Nguyen GC, Elnahas A, Jackson TD. The impact of preoperative steroid use on short-term outcomes following surgery for inflammatory bowel disease. J Crohns Colitis 2014;8:1661-7.

37. Billioud V, Ford AC, Tedesco ED, et al. Preoperative use of anti-TNF therapy and postoperative complications in inflammatory bowel disease: a meta-analysis. J Crohns Colitis 2013;7:853-67.

38. Yang ZP, Hong L, Wu Q, et al. Preoperative infliximab use and postoperative complications in Crohn's disease: a systematic review and meta-analysis. Int J Surg 2014;12:224-30.

39. Mitsuya JB, Gonzalez R, Thomas R, et al. The Effect of Biologics on Postoperative Complications in Children With Inflammatory Bowel Disease and Bowel Resection. J Pediatr Gastroenterol Nutr 2019;68:334-8.

40. Zimmerman LA, Saites CG, Bairdain S, et al. Postoperative Complications in Children with Crohn Disease Treated with Infliximab. J Pediatr Gastroenterol Nutr 2016;63:352-6.

41. Abbas PI, Peterson ML, Fallon SC, et al. Evaluating the impact of infliximab use on surgical outcomes in pediatric Crohn's disease. J Pediatr Surg 2016;51:786-9.

42. Yamamoto T, Allan RN, Keighley MR. Risk factors for intra-abdominal sepsis after surgery in Crohn's disease. Dis Colon Rectum 2000;43:1141-5.

43. Alves A, Panis Y, Bouhnik Y, et al. Risk factors for intraabdominal septic complications after a first ileocaecal resection for Crohn's disease: a multivariate analysis in 161 consecutive patients. Dis Colon Rectum 2007;50:331-6.

44. Jacobson S. Early postoperative complications in patients with Crohn's disease given and not given preoperative total parenteral nutrition. Scand J Gastroenterol 2012;47:170-7.

45. Nylund CM, Goudie A, Garza JM, et al. Venous thrombotic events in hospitalized children and adolescents with inflammatory bowel disease. J Pediatr Gastroenterol Nutr 2013;56:485-91.

46. Valman HB, Roberts PD. Vitamin B12 absorption after resection of ileum in childhood. Arch Dis Child 1974;49:932-5.

47. Ooi BC, Barnes GL, Tauro GP. Normalization of vitamin B12 absorption after ileal resection in children. J Paediatr Child Health 1992;28:168-71.

48. Gothe F, Beigel F, Rust C, et al. Bile acid malabsorption assessed by 7 alpha-hydroxy-4-cholesten-3-one in paediatric inflammatory bowel disease: correlation to clinical and laboratory findings. J Crohns Colitis 2014;8:1072-8.

49. Turner D, Otley AR, Mack D, et al. Development, validation, and evaluation of a pediatric ulcerative colitis activity index: a prospective multicenter study. Gastroenterology 2007;133:423-32.

50. Turner D, Hyams J, Markowitz J, et al. Appraisal of the pediatric ulcerative colitis activity index (PUCAI). Inflamm Bowel Dis 2009;15:1218-23.

51. Soon IS, de Bruyn JC, Hubbard J, et al. Rising postcolectomy complications in children with ulcerative colitis despite stable colectomy rates in United States. J Crohns Colitis 2014;8:1417-26.

52. Benchimol EI, Guttmann A, To T, et al. Changes to surgical and hospitalization rates of pediatric inflammatory bowel disease in Ontario, Canada (1994-2007). Inflamm Bowel Dis 2011;17:2153-61.

53. Aloi M, D'Arcangelo G, Pofi F, et al. Presenting features and disease course of pediatric ulcerative colitis. J Crohns Colitis 2013;7:e509-15.

54. Schechter A, Griffiths C, Gana JC, et al. Early endoscopic, laboratory and clinical predictors of poor disease course in paediatric ulcerative colitis. Gut 2015;64:580-8.

55. Truelove SC, Jewell DP. Intensive intravenous regimen for severe attacks of ulcerative colitis. Lancet 1974;1:1067-70.

56. Turner D, Ruemmele FM, Orlanski-Meyer E, et al. Management of Paediatric Ulcerative Colitis, Part 2: Acute Severe Colitis-An Evidence-based Consensus Guideline from the European Crohn's and Colitis Organization and the European Society of Paediatric Gastroenterology, 
Hepatology and Nutrition. J Pediatr Gastroenterol Nutr 2018;67:292-310.

57. Russell RK, Protheroe A, Roughton M, et al. Contemporary outcomes for ulcerative colitis inpatients admitted to pediatric hospitals in the United Kingdom. Inflamm Bowel Dis 2013;19:1434-40.

58. Turner D, Travis SP, Griffiths AM, et al. Consensus for managing acute severe ulcerative colitis in children: a systematic review and joint statement from ECCO, ESPGHAN, and the Porto IBD Working Group of ESPGHAN. Am J Gastroenterol 2011;106:574-88.

59. Turner D, Walsh CM, Benchimol EI, et al. Severe paediatric ulcerative colitis: incidence, outcomes and optimal timing for second-line therapy. Gut 2008;57:331-8.

60. Turner D, Griffiths AM. Acute severe ulcerative colitis in children: a systematic review. Inflamm Bowel Dis 2011;17:440-9.

61. Turner D, Walsh CM, Steinhart AH, et al. Response to corticosteroids in severe ulcerative colitis: a systematic review of the literature and a meta-regression. Clin Gastroenterol Hepatol 2007;5:103-10.

62. Turner D, Mack D, Leleiko N, et al. Severe pediatric ulcerative colitis: a prospective multicenter study of outcomes and predictors of response. Gastroenterology 2010;138:2282-91.

63. Aloi M, D’Arcangelo G, Capponi M, et al. Managing pediatric acute severe ulcerative colitis according to the 2011 ECCO-ESPGHAN guidelines: Efficacy of infliximab as a rescue therapy. Dig Liver Dis 2015;47:455-9.

64. Turner D, Ruemmele FM, Orlanski-Meyer E, et al. Management of Paediatric Ulcerative Colitis, Part 1: Ambulatory Care-An Evidence-based Guideline from European Crohn's and Colitis Organization and European Society of Paediatric Gastroenterology, Hepatology and Nutrition. J Pediatr Gastroenterol Nutr 2018;67:257-91.

65. Fraser JD, Garey CL, Laituri CA, et al. Outcomes of laparoscopic and open total colectomy in the pediatric population. J Laparoendosc Adv Surg Tech A 2010;20:659-60.

66. Chatzizacharias NA, Torrente F, Brennan M, et al. Single port laparoscopic subtotal colectomy and ileostomy in an adolescent with ulcerative colitis. J Crohns Colitis 2012;6:1031-3.

67. Singh P, Bhangu A, Nicholls RJ, et al. A systematic review and meta-analysis of laparoscopic vs open restorative proctcolectomy. Colorectal Dis 2013;15:e340-51.

68. Georgeson KE. Laparoscopic-assisted total colectomy with pouch reconstruction. Semin Pediatr Surg 2002;11:233-6.

69. Linden BC, Bairdain S, Zurakowski D, et al. Comparison of laparoscopic-assisted and open total proctocolectomy and ileal pouch anal anastomosis in children and adolescents. J Pediatr Surg 2013;48:1546-50.

70. Ozdemir Y, Kiran RP, Erem HH, et al. Functional outcomes and complications after restorative proctocolectomy and ileal pouch anal anastomosis in the pediatric population. J Am Coll Surg 2014;218:328-35.

71. Ryan DP, Doody DP. Restorative proctocolectomy with and without protective ileostomy in a pediatric population. J Pediatr Surg 2011;46:200-3.

72. Gray BW, Drongowski RA, Hirschl RB, et al. Restorative proctocolectomy without diverting ileostomy in children with ulcerative colitis. J Pediatr Surg 2012;47:204-8.

73. Tilney HS, Constantinides V, Ioannides AS, et al. Pouch-anal anastomosis vs straight ileoanal anastomosis in pediatric patients: a meta-analysis. J Pediatr Surg 2006;41:1799-808.

74. Durno C, Sherman P, Harris K, et al. Outcome after ileoanal anastomosis in pediatric patients with ulcerative colitis. J Pediatr Gastroenterol Nutr 1998;27:501-7.

75. Seetharamaiah R, West BT, Ignash SJ, et al. Outcomes in pediatric patients undergoing straight vs $\mathrm{J}$ pouch ileoanal anastomosis: a multicenter analysis. J Pediatr Surg 2009;44:1410-7.

76. Lovegrove RE, Constantinides VA, Heriot AG, et al. A comparison of hand-sewn versus stapled ileal pouch anal anastomosis (IPAA) following proctocolectomy: a metaanalysis of 4183 patients. Ann Surg 2006;244:18-26.

77. Davis C, Alexander F, Lavery I, et al. Results of mucosal proctectomy versus extrarectal dissection for ulcerative colitis and familial polyposis in children and young adults. J Pediatr Surg 1994;29:305-9.

78. Luukkonen $P$, Järvinen H. Stapled vs hand-sutured ileoanal anastomosis in restorative proctocolectomy. A prospective randomized study. Arch Surg 1993;128:437-40.

79. Polites SF, Potter DD, Moir CR, et al. Long-term outcomes of ileal pouch-anal anastomosis for pediatric chronic ulcerative colitis. J Pediatr Surg 2015;50:1625-9.

80. Soon IS, Wrobel I, de Bruyn JC, et al. Postoperative complications following colectomy for ulcerative colitis in children. J Pediatr Gastroenterol Nutr 2012;54:763-8.

81. Markel TA, Lou DC, Pffeferkorn M, et al. Steroids and poor nutrition are associated with infectious wound complications in children undergoing first stage procedures for ulcerative colitis. Surgery 2008;144:540-5.

82. Lazzerini M, Bramuozzo M, Maschio M, et al. 
Thromboembolism in pediatric inflammatory bowel disease: systematic review. Inflamm Bowel Dis 2011;17:2174-83.

83. Pakarinen MP, Natunen J, Ashorn M, et al. Long-term outcomes of restorative proctocolectomy in children with ulcerative colitis. Pediatrics 2009;123:1377-82.

84. Patton D, Gupta N, Wojcicki JM, et al. Postoperative outcome of colectomy for pediatric patients with ulcerative colitis. J Pediatr Gastroenterol Nutr 2010;51:151-4.

85. Perrault J. Pouchitis in Children: Therapeutic Options. Curr Treat Options Gastroenterol 2002;5:389-97.

86. Orlanski-Meyer E, Topf-Olivestone C, Ledder O, et al. Pouchitis in Paediatric UC: A multicenter longitudinal cohort study from the Porto IBD working group of ESPGHAN. Prague: ESPGHAN Annual Meeting, 2017:Abstr G-O-038.

87. Meagher AP, Farouk R, Dozois RR, et al. J ileal pouch-anal anastomosis for chronic ulcerative colitis: complications and long-term outcome in 1310 patients. Br J Surg 1998;85:800-3.

88. Hurst RD, Molinari M, Chung TP, et al. Prospective study of the incidence, timing and treatment of pouchitis in 104 consecutive patients after restorative proctocolectomy. Arch Surg 1996;131:497-500; discussion 501-2.

89. Sandborn WJ, Pouchitis following ileal pouch-anal anastomosis: definition, pathogenesis, and treatment. Gastroenterology 1994;107:1856-60.

90. Murrell Z, Vasiliauskas E, Melmed G, et al. Preoperative wireless capsule endoscopy does not predict outcome after ileal pouch-anal anastomosis. Dis Colon Rectum 2010;53:293-300.

91. Zaghiyan K, Kamiński JP, Barmparas G, et al. De novo Crohn's Disease after Ileal Pouch-Anal Anastomosis for Ulcerative Colitis and Inflammatory Bowel Disease Unclassified: Long-Term Follow-Up of a Prospective Inflammatory Bowel Disease Registry. Am Surg 2016;82:977-81.

92. Dharmaraj R, Dasgupta M, Simpson P, et al. Predictors of Pouchitis After Ileal Pouch-Anal Anastomosis in Children. J Pediatr Gastroenterol Nutr 2016;63:e210-1.

93. Burns EM, Bottle A, Aylin P, et al. Volume analysis of outcome following restorative proctocolectomy. Br J Surg 2011;98:408-17.

94. Shen B, Achkar JP, Lashner BA, et al. A randomized clinical trial of ciprofloxacin and metronidazole to treat acute pouchitis. Inflamm Bowel Dis 2001;7:301-5.

95. Gionchetti P, Rizzello F, Poggioli G, et al. Oral budesonide in the treatment of chronic refractory pouchitis. Aliment Pharmacol Ther 2007;25:1231-6.

96. Ferrante M, D'Haens G, Dewit O, et al. Efficacy of infliximab in refractory pouchitis and Crohn's diseaserelated complications of the pouch: a Belgian case series. Inflamm Bowel Dis 2010;16:243-9.

97. Michelassi F, Lee J, Rubin M, et al. Long-term functional results after ileal pouch anal restorative proctocolectomy for ulcerative colitis: a prospective observational study. Ann Surg 2003;238:433-41.

98. Nyholm I, Hukkinen M, Koivusalo A, et al. Long-term Single-centre Outcomes After Proctocolectomy With Ileoanal Anastomosis for Paediatric Ulcerative Colitis. J Crohns Colitis 2019;13:302-8.

99. Abdelaal K, Jaffray B. Colonic disease site and perioperative complications predict need for later intestinal interventions following intestinal resection in pediatric Crohn's disease. J Pediatr Surg 2016;51:272-6.

100. Willoughby CP, Truelove SC. UIcerative colitis and pregnancy. Gut 1980;21:469-74.

101.Hudson M, Flett G, Sinclair TS, et al. Fertility and pregnancy in inflammatory bowel disease. Int J Gynaecol Obstet 1997;58:229-37.

102. Olsen KO, Joelsson M, Laurberg S, et al. Fertility after ileal pouch-anal anastomosis in women with ulcerative colitis. Br J Surg 1999;86:493-5.

103. Shannon A, Eng K, Kay M, et al. Long-term follow up of ileal pouch anal anastomosis in a large cohort of pediatric and young adult patients with ulcerative colitis. J Pediatr Surg 2016;51:1181-6.

104. Rajaratnam SG, Eglinton TW, Hider P, et al. Impact of ileal pouch-anal anastomosis on female fertility: metaanalysis and systematic review. Int J Colorectal Dis 2011;26:1365-74.

105.Öresland T, Palmblad S, Ellström M, et al. Gynaecological and sexual function related to anatomical changes in the female pelvis after restorative proctocolectomy. Int J Colorectal Dis 1994;9:77-81.

106. Asztély M, Palmblad S, Wikland M, et al. Radiological study of changes in the pelvis in women following proctocolectomy. Int J Colorectal Dis 1991;6:103-7.

107. Wikland M, Jansson I, Asztély M, et al. Gynaecological problems related to anatomical changes after conventional proctocolectomy and ileostomy. Int J Colorectal Dis 1990;5:49-52.

108. Gorgun E, Remzi FH, Goldberg JM, et al. Fertility is reduced after restorative proctocolectomy with ileal pouch anal anastomosis: a study of 300 patients. Surgery 
2004;136:795-803.

109. Johnson P, Richard C, Ravid A, et al. Female infertility after ileal pouch-anal anastomosis for ulcerative colitis. Dis Colon Rectum 2004;47:1119-26.

Cite this article as: Kelay A, Tullie L, Stanton M. Surgery and paediatric inflammatory bowel disease. Transl Pediatr 2019;8(5):436-448. doi: 10.21037/tp.2019.09.01
110. Beyer-Berjot L, Maggiori L, Birnbaum D, et al. A total laparoscopic approach reduces the infertility rate after ileal pouch-anal anastomosis: a 2-center study. Ann Surg 2013;258:275-82. 